\title{
Guest Editorial to the CouFrac 2018 Special Issue Coupled Thermal-Hydro-Mechanical-Chemical Processes in Fractured Media: Microscale to Macroscale Numerical Modeling
}

\author{
Mengsu Hu ${ }^{1} \cdot$ Carl I. Steefel $^{1} \cdot$ Jonny Rutqvist ${ }^{1}$ \\ Published online: 7 October 2020 \\ (C) This is a U.S. Government work and not under copyright protection in the US; foreign copyright protection may apply 2020
}

\section{Introduction}

Driven by the growing interest in coupled processes in fractured media, the International Conference on Coupled Processes in Fractured Geological Media: Observation, Modeling, and Application (CouFrac) was established and chaired by Jonny Rutqvist from the Lawrence Berkeley National Laboratory. The first conference was held in Wuhan, China in 2018 with over 100 presentations including numerical methods, in situ tests, laboratory experiments, and applications to different subsurface engineering activities involving coupled processes. In this special issue, presentations focused on numerical modeling of microscale (micron to centimeter) to macroscale (meter to kilometer) thermal-hydromechanical-chemical (THMC) coupled processes in fractured media were invited to develop full-length peer-reviewed research manuscripts.

\section{Advances in numerical modeling of coupled processes in fractured media}

With the development of computational and numerical capabilities in combination with new numerical methods, numerical modeling of coupled processes in fractured media has been greatly advanced with more realistic representation of discrete fractures for analyzing subsurface geosciences, with enhanced understanding of microscale behavior of fractures, and with more complete sets of physics at multiple temporal and spatial scales. This special issue covers all these aspects.

Mengsu $\mathrm{Hu}$

mengsuhu@lbl.gov

1 Energy Geosciences Division, Lawrence Berkeley National Laboratory, Berkeley, CA, USA

\subsection{Development of novel numerical methods}

Motivated by the fact that a number of simulators for fluid flow calculation have been developed based on the finite difference or finite volume methods, a new finite volume model for coupling fluid flow, heat transfer, and mechanics was developed by Hu and Rutqvist [1]. In that model, in addition to full coupling between flow and heat transfer and geomechanics, brine migration as a result of chemical dissolution and precipitation due to temperature gradients was implicitly considered using a dual-continuum model.

In order to simulate complex hydraulic fracturing processes such as fracture branching and coalescence of natural and hydraulic fractures, a new phase field model was developed by $\mathrm{Ni}$ et al. [2]. In their approach, discrete natural and hydraulic fractures are represented with continuous diffused damage domains.

\subsection{From macroscale to microscale modeling}

As the field has progressed from macroscale to microscale numerical modeling, geometric features and governing equations that describe the physical behavior of fractured media are quite different. Because of complex evolving geometric features that are discontinuous, microscale modeling of coupled processes is very challenging.

For the first time, Hu and Rutqvist [3] developed a microscale mechanical model that can simulate dynamic contacts of deformable geomaterials. In their approach, separation, bonding, and slip between microscale material bodies can be simulated as well as tensile and/or shear failure at the grain boundaries. This model can be applied to analyze fractures with explicit representation of asperities that can move, deform, and accumulate high stresses. In addition, this new model can simulate the dynamics of both loosely and tightly packed granular systems, and failure and fragmentation of cemented geomaterials. 
To tackle the challenges in analyzing coupled hydromechanical processes at fracture intersections involving contacts, Planta et al. [4] developed a model based on the fictitious domain method with variational transfer operators to enable transfer of physical variables between the solid and NavierStokes fluid flow with different meshes. The model can capture fluid-solid boundaries of realistic fracture geometries with complex surface topographies and intersections while considering opening and closure states of the fractures.

\subsection{Coupling with additional physics}

Several of the papers in the Special Issue considered the coupling of additional complex physics.

In a study of the use of supercritical carbon dioxide (SC$\mathrm{CO}_{2}$ ) as a working fluid for hydraulic fracturing, $\mathrm{Li}$ et al. [5] developed a new coupled fluid-solid model based on the discrete element method (DEM). Based on a number of simulations, including comparison with high-viscosity fracturing fluid, the authors concluded that $\mathrm{SC}-\mathrm{CO}_{2}$ could be an alternative fracturing fluid to induce more effective fracture networks for hydrocarbon production.

Focusing on thermally induced damage, Wu et al. [6] used a 3D-coupled FEM-DEM method with cohesive elements to represent pre-existing fractures. The authors studied thermally induced damage in different settings of complex fractures within a Brazilian disc and show the impact of average fracture aperture on the Brazilian tensile strength.

Chemical impacts on fluid and heat transfer and mechanics have attracted growing interest in recent years. In this special issue, three manuscripts examined such impacts.

In order to study the long-term evolution in rock permeability due to mineral reactions (i.e., pressure solution and free-face dissolution/precipitation), Ogata et al. [7] developed a new model that considers fracture initiation and propagation as a result of the coupled THMC processes and applied it to analyze long-term changes in the permeability of rock at a high-level radioactive waste repository. The results show that pressure solution at the contacting asperities of generated fractures can reduce permeability in the excavation damage zone by one order of magnitude.

Using a phase field lattice-Boltzmann method, Ahkami et al. [8] studied pore-scale behavior of single-species mineral precipitation reactions in a fractured porous medium. The authors investigated diffusion and reaction in advectiondominated and diffusion-dominated regimes, as well as transport-limited and reaction-limited regimes. A relationship between mineral precipitation pattern, porosity, and permeability was established based on the modeling.

Zhang et al. [9] used the TOUGHREACT simulator to study the potential of uranium release as a result of $\mathrm{CO}_{2}$ injection and the impact of various factors on uranium release rate involving a single fracture. They concluded that the environmental risk of $\mathrm{CO}_{2}$-induced uranium release is quite low in the scenario they investigated.

\subsection{Inversion for analyzing coupled processes in fractured media}

Two manuscripts investigated the use of inversion for the analysis of coupled processes in fractured media.

The study of Commer et al. [10] investigates the potential of the surface-based time-domain electromagnetic (EM) method. They carried out investigations within a hydrogeophysical parameter estimation framework in which EM data and injection flow rates are combined in a fully coupled way.

A study by Blaheta et al. [11] presented an approach based on the concept of porous media as a continuum within which fractures can be represented as lower dimensional objects. The implementation of a Bayesian inversion is realized via Metropolis-Hastings Markov chain Monte Carlo approach with a sampling procedure that uses the delayed acceptance of samples based on a surrogate model.

\section{References}

1. Hu, M., Rutqvist, J.: Finite volume modeling of coupled thermohydro-mechanical processes with application to brine migration in salt. Comput. Geosci. (2020a). https://doi.org/10.1007/s10596020-09943-8

2. Ni, L., Zhuang, X., Zou, L., Huang, J.: Phase-field modeling of hydraulic fracture network propagation in poroelastic rocks. Comput. Geosci. (2020). https://doi.org/10.1007/s10596-02009955-4

3. Hu, M., Rutqvist, J.: Microscale mechanical modeling of deformable geomaterials with dynamic contacts based on the numerical manifold method. Comput. Geosci. (2020b). https://doi.org/10. 1007/s10596-020-09992-Z

4. Planta, C.V., Vogler, D., Chen, X., Nestola, M.G., Saar, M.O., Krause, R.: Modelling of hydro-mechanical processes in heterogeneous fracture intersections using a fictitious domain method with variational transfer operators. Comput. Geosci. (2020). https://doi. org/10.1007/s10596-020-09936-7

5. Li, M., Zhang, F., Zhuang, L., Zhang, X., Ranjith, P.: Micromechanical analysis of hydraulic fracturing in the toughness-dominated regime: implications to supercritical carbon dioxide fracturing. Comput. Geosci. (2020). https://doi.org/10. 1007/s10596-019-09925-5

6. Wu, Z., Zhou, Y., Weng, L., Liu, Q., Xiao, Y.: Investigation of thermal-induced damage in fractured rock mass by coupled FEMDEM method. Comput. Geosci. (2020). https://doi.org/10.1007/ s10596-020-09970-5

7. Ogata, S., Yasuhara, H., Kinoshita, N., Kishida, K.: Coupled thermal-hydraulic-mechanical-chemical modeling for permeability evolution of rocks through fracture generation and subsequent sealing. Comput. Geosci. (2020). https://doi.org/10.1007/s10596020-09948-3

8. Ahkami, M., Parmigiani, A., Palma, P.R.D., Saar, M.O., Kong, X.Z.: A lattice-Boltzmann study of permeability-porosity 
relationships and mineral precipitation patterns in fractured porous media. Comput. Geosci. (2020). https://doi.org/10.1007/s10596019-09926-4

9. Zhang, L., Miao, X., Wang, B., Liu, H., Wang, Y., Gan, M., Li, X.: Uranium release surrounding a single fracture in a uranium-rich reservoir under geologic carbon storage conditions. Comput. Geosci. (2020). https://doi.org/10.1007/s10596-020-09974-1

10. Commer, M., Finsterle, S., Hoversten, G.M.: Three-dimensional fracture continuum characterization aided by surface time-domain electromagnetics and hydrogeophysical joint inversion - proof-of- concept. Comput. Geosci. (2020). https://doi.org/10.1007/s10596020-09942-9

11. Blaheta, R., Beres, M., Domesova, S., Horak, D.: Bayesian inversion for steady flow in fractured porous media with contact on fractures and hydro-mechanical coupling. Comput. Geosci. (2020). https://doi.org/10.1007/s10596-020-09935-8

Publisher's note Springer Nature remains neutral with regard to jurisdictional claims in published maps and institutional affiliations. 